\title{
Optimizing Design Layout of a Riverside Residential Settlement in terms of the Thermal Comfort
}

\author{
Lei Yu ${ }^{1,2,3, *}$, Jing Liu ${ }^{2,4}$, Jingwen Tao ${ }^{1,2,3}$ \\ ${ }^{1}$ School of Architecture, Harbin Institute of Technology, Shenzhen, China \\ ${ }^{2}$ Shenzhen Key Laboratory of Urban Planning and Decision-Making, Shenzhen, China \\ ${ }^{3}$ Shanghai Key Laboratory of Urban Renewal and Spatial Optimization Technology, Shanghai, China \\ ${ }^{4}$ School of Architecture, Harbin Institute of Technology, Harbin, China
}

\section{Email address: \\ Leilayu@hit.edu.cn (Lei Yu) \\ ${ }^{*}$ Corresponding author}

\section{To cite this article:}

Lei Yu, Jing Liu, Jingwen Tao. Optimizing Design Layout of a Riverside Residential Settlement in terms of the Thermal Comfort. Landscape Architecture and Regional Planning. Vol. 4, No. 4, 2019, pp. 87-95. doi: 10.11648/j.larp.20190404.14

Received: October 6, 2019; Accepted: December 11, 2019; Published: December 30, 2019

\begin{abstract}
The thermal comfort of a riverside residential settlement differs from a non-riverside residential one, which might be caused by a microclimatic difference. Inducing wind from a river to cross the whole riverside residential settlement could improve the outdoor thermal comfort significantly. Such knowledge triggers a study of utilizing river wind to enhance thermal comfort to a riverside residential settlement in southern China. The study explores various possible layouts of a riverside residential settlement using Computational Fluid Dynamic (CFD) simulations. The thermal comfort index OUT_SET* (the Standard Effective Temperature) that combines effects of air temperature, radiation, wind velocity, and the water evaporation, has been used to evaluate thermal comfort of various riverside residential settlements due to different design layouts. The result showed that the loose enclosed layout is the best one for the thermal comfort whereas the back and front aligned determinant layout is the worst. In order to apply the results into a real world, a case study has been made to the Shenzhen Nan Hua Cun. The thermal environment of this Chinese southern riverside residential settlement has been researched. According to thermal problems revealed by CFD simulation, an optimization design layout was proposed by applying the study results. Eventually, the thermal comfort between the current situation and the optimization design has been compared.
\end{abstract}

Keywords: Design Layout, Outdoor Space, Thermal Comfort, Riverside Residential Settlement

\section{Introduction}

"Heat Islands" have serious influence on urban thermal environment. This fact is being increasingly recognised when doing a design [1]. Among the various approaches of reducing heat island effects, use of a water body is emphasized as having a cooling action. A microclimate produced by a waterbody is usually considered when designing a riverside settlement, especially in the subtropical regions. Many studies have been done on the use of water bodies to ease heat effects [2-5], but a few studies have paid an attention of water body effect on thermal comfort for design purposes $[6,7]$. Gaitani et al. found that a large green area or water body could obviously improve its surrounding thermal environment [8]. Martínez-Arroyo and Jáuregui observed that, in addition to benefit thermal comfort, a water body could increase conversions between oxygen and carbon dioxide and thus decrease carbon dioxide levels [9]. These studies showed that water bodies, especially large ones, could enhance the surrounding environments. Therefore, such a good effect brought by a water body should be taken into account in a design.

In order to assess outdoor thermal comfort, a number of indices have been developed [10-13]. However, no universal norm is found in measuring thermal comfort. Many factors of temperature, humidity, wind speed, and solar radiation should be included. By analysing relationships between temperature, humidity, and average wind velocity, Ahmed concluded that $27.5-33^{\circ} \mathrm{C}$ is a comfortable temperature for outdoor spaces [14]. Although solar radiation is not usually taken in calculating thermal comfort, a study by Yang et al. made in 
Singapore has found that solar radiation is a main factor in thermal comfort when the air temperature is around 26.3$31.7^{\circ} \mathrm{C}$ [15]. Some standards have been developed to assess outdoor thermal comfort, of which PET (Physiological Equivalent Temperature) and SET (Standard Effective Temperature) are widely employed [16-20]. Makaremi et al. used PET to study the shade influence on thermal comfort that found a correct degree of shading is useful [16]. Spagnolo and Dear used SET to compare the differences in thermal comfort between indoor and outdoor spaces. They found that the outdoor thermal comfort was significantly higher than the indoor thermal comfort [19].

Since water bodies have great benefits on modulating thermal comfort and mitigating heat island, it is considered that a river in a subtropical area should be valuable for improving thermal comfort in the summer. Although studies have been made on design alternatives to improve thermal environments in outdoor spaces [21-24], less work has focused on exploring design layouts of riverside residential settlements due to waterbody influences. The purpose of this study is to explore design approaches in utilizing the river benefit to reduce heat effects and improve outdoor thermal comfort to a riverside residential settlement in the Chinese subtropical area. Using Computational Fluid Dynamic (CFD) simulations, various design layouts of riverside residential settlements are compared and the optimization ones are gained. Their effectiveness in achieving thermal comfort are also tested. Finally, a case study in Shenzhen Nan Hua Residential Settlement was made by applying the study results.

\section{Methodology}

In order to study the influence of a waterbody on the thermal comfort of a riverside residential settlement, a CFD technique is applied. In the study, numerical simulations have been made to various design layout of a riverside residential settlement. A turbulence model was developed in the simulation in order to take hydraulic effects of a waterbody into account. A moisture distribution model was also developed and integrated into the simulations. Based on the results of the simulations, the thermal comfort of a riverside residential settlement according to various design layouts was explored.

\subsection{Physical Study Models}

While studying the influence of a waterbody on the thermal comfort of a riverside residential settlement, typical models representing possible design layouts were derived. Based on numerous case studies of a real world, thirteen design models representing typical design layouts were developed. Amongst them, three primary layouts namely determinant layout, enclosed layout, and point group layout can be concluded, which are mostly used in a residential settlement in a subtropical area. According to variation of the three primary layouts, four model types named A, B, C, and D were defined as shown in the Table 1 . All the design models were assigned with a similar size in order to compare the layout differences, which has a length and width around $200-300 \mathrm{~m}$, an area of 5 -6 ha, a Floor-area Ratio (FAR) of $2.5-3$.

The A design models include all variations of the three primary layouts but without any changes of other design features. Then, the A models were further categorized into three, namely A-a, A-b, A-c. The A-a models represent possible occurrence situations of the building arrangement of a determinant layout. Furthermore, three options of the A-a models can be extracted, which is named A-a1, A-a2, A-a3. The A-a1 deign model represents the regularly aligned determinant layout. The A-a2 design model represents the situation of the front and back aligned determinant layout, while the A-a3 represents the right and left aligned determinant layout. The A-b models represent possible occurrence situations of the building arrangement of an enclosed layout. Amongst them, the A-b1 represents the enclosed whereas the A-b2 represents the loosely enclosed. The A-c models represent possible occurrence situations of the building arrangement of point group layout. The A-c1 model represents regular point group layout, while the A-c2 model represents irregular point group layout.

Table 1. Study models and thermal parameters: $A T, R H$ and $W V$.

\begin{tabular}{|c|c|c|c|c|c|c|c|}
\hline No & Layout & AT & Avg. AT & RH & Avg. RH & WV & Avg. WV \\
\hline A-a1 & & & $36.1^{\circ} \mathrm{C}$ & 트르르믐 & $48.7 \%$ & 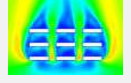 & $1.2 \mathrm{~m} / \mathrm{s}$ \\
\hline $\mathrm{A}-\mathrm{a} 2$ & & & $36.5^{\circ} \mathrm{C}$ & & $46.3 \%$ &  & $1.3 \mathrm{~m} / \mathrm{s}$ \\
\hline A-a3 & & & $35^{\circ} \mathrm{C}$ & & $50 \%$ & 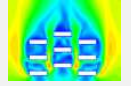 & $1.5 \mathrm{~m} / \mathrm{s}$ \\
\hline A-b1 & & 5 & $33.4^{\circ} \mathrm{C}$ & 77 & $45.2 \%$ & $\left(\begin{array}{ll}4 \\
7\end{array}\right)$ & $1.9 \mathrm{~m} / \mathrm{s}$ \\
\hline
\end{tabular}




\begin{tabular}{|c|c|c|c|c|c|c|c|}
\hline No & Layout & AT & Avg. AT & RH & Avg. RH & WV & Avg. WV \\
\hline A-b2 & & & $31.3^{\circ} \mathrm{C}$ & & $54.5 \%$ & ifla & $2.6 \mathrm{~m} / \mathrm{s}$ \\
\hline A-c1 & & & $32.8^{\circ} \mathrm{C}$ & & $52.3 \%$ & 题 & $2.4 \mathrm{~m} / \mathrm{s}$ \\
\hline A-c2 & & & $33.6^{\circ} \mathrm{C}$ & & $47.7 \%$ & & $2 \mathrm{~m} / \mathrm{s}$ \\
\hline B-1 & & & $33.8^{\circ} \mathrm{C}$ & & $50.1 \%$ & & $2.1 \mathrm{~m} / \mathrm{s}$ \\
\hline B-2 & & & $33.1^{\circ} \mathrm{C}$ & & $64.4 \%$ & & $2.7 \mathrm{~m} / \mathrm{s}$ \\
\hline B-3 & & & $34.2^{\circ} \mathrm{C}$ & & $50.1 \%$ & & $2.1 \mathrm{~m} / \mathrm{s}$ \\
\hline $\mathrm{C}$ & & & $35.3^{\circ} \mathrm{C}$ & & $52.3 \%$ & & $1.6 \mathrm{~m} / \mathrm{s}$ \\
\hline D-1 & & & $35.5^{\circ} \mathrm{C}$ & & $45.2 \%$ & $\frac{1}{2} \frac{1}{2}$ & $1.5 \mathrm{~m} / \mathrm{s}$ \\
\hline D-2 & & & $35.9^{\circ} \mathrm{C}$ & & $42.3 \%$ & 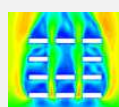 & $1.3 \mathrm{~m} / \mathrm{s}$ \\
\hline
\end{tabular}

The $\mathrm{B}, \mathrm{C}$, and $\mathrm{D}$ design models present the layout variations of building orientation, building height, and open space of a residential settlement. Although all the A models could have above variations, the study only chose the A-a1 model to make a comparison because it is most used in a residential settlement design and can stand for the other two primary layouts. The $\mathrm{B}$ design models present the layout variations of building orientation. To the B design models, the B-1 presents a layout of the buildings having $45^{\circ}$ angle with the river, the B-2 having $90^{\circ}$, and the B-3 having $135^{\circ}$. The layout of the buildings having a $0^{\circ}$ angle to the river is just the $\mathrm{A}-\mathrm{a} 1$ design model. The $\mathrm{C}$ design model represents a variation of the buildings' height in terms of distance to the river. Because of only one suitable layout of the buildings' height when considering wind penetration to the whole settlement, there is only one model of the $\mathrm{C}$ that is the buildings' height is lowering with closer to the river. Other variation of the buildings' heights would hinder wind penetration and mitigate the thermal comfort. The D design models present the layout variations of the open space. To the $\mathrm{D}$ design models, the D-1 presents the open space located in the area closer to the river, and the D-2 presents the open space located in the area far away from the river. These two models will be compared with the A-al model that presents a layout without an open space.

Totally, 13 typical design models were developed to explore the thermal comfort of a riverside residential settlement in terms of various design layouts. Using microclimatic data measured in a typical summer day, the distributions of air temperature (AT), relative humidity (RH), and wind velocity (WV) were calculated through the CFD simulations; and the average values of these parameters were also calculated. The developed design models and their simulation results are shown in the Table 1.

\subsection{Simulation Model Configuration}

In simulating the thermal comfort of a riverside residential settlement, water evaporation effect has to be considered in the CFD simulations. A precise model to simulate moisture dispersal around water bodies was developed as a part of the simulations, which is based on a study of the hydraulic effects of water bodies on the microclimate of a waterside pedestrian [6], a Re-Normalization Group k- $\varepsilon$ (RNG) turbulence model was integrated. The humidity difference between the air above the water body and the higher layers of the atmosphere has been taken into account, the amount of water evaporation can be calculated using the bulk coefficient equation [6]:

$$
\mathrm{E} \varepsilon=\mathrm{p}_{\mathrm{a}} \mathrm{c}_{\mathrm{t}} \mathrm{u}\left(\mathrm{q}_{\mathrm{s}}-\mathrm{q}_{\mathrm{a}}\right)
$$

where $\mathrm{E} \varepsilon$ is the evaporation rate at the water-air interface; pa is 
the density of air, $\mathrm{kg} / \mathrm{m} 3$; ct is the bulk empirical coefficient (ct $=0.00115$, when wind velocity is less than $5 \mathrm{~m} / \mathrm{s}$, as in this CFD simulation); $\mathrm{u}$ is the wind velocity at a certain height from the ground, $\mathrm{m} / \mathrm{s}$; qs is the saturated moisture content near water surface, $\mathrm{kg} / \mathrm{kg}$; and qa is the moisture content of the air above the water, $\mathrm{kg} / \mathrm{kg}$.

In addition, setting up a suitable computational domain size is also crucial. It was found that a medium grid resolution of approximately $1.5 \times 106$ has sufficient accuracy and an appropriate calculation time to study the thermal environment of on-shore building arrangement [6]. Therefore, the computational domain size in the study was set as $1500 \mathrm{~m}$ length, $1000 \mathrm{~m}$ width, and $200 \mathrm{~m}$ height, which is suitable for all the design models. For computational conditions, a typical summer afternoon in July, from 13:00 to 14:00, was chosen; the microclimatic data were obtained via field measurements at a river in Shenzhen, which is a metropolis in southern China adjacent to Hong Kong. The selected river was obtained after exploring numerous rivers in Shenzhen, the typical one is the $130 \mathrm{~m}$ wide flowing from north to south. The microclimatic data of the measurement is that the WV is $2.5 \mathrm{~m} / \mathrm{s}$, the AT is $28.9^{\circ} \mathrm{C}$, the $\mathrm{RH}$ is $60 \%$, and the local temperature is $24.3^{\circ} \mathrm{C}$. These data as the computational conditions were input into the simulations.

\subsection{Thermal Comfort}

An assessment standard for the thermal comfort is needed in the study. Thermal comfort literally refers to a person's evaluation of the comfort of a thermal environment. While using thermal comfort to judge a thermal environment, many physical parameters have to be considered including air temperature (AT), relative humidity $(\mathrm{RH})$, wind velocity (WV), and solar radiation. As discussed in Section 1, there is more than one assessment standard for evaluating thermal comfort. The OUT_SET is adopted in this study as it is often used to evaluate the thermal comfort of outdoor environment $[18,19,24]$. According the Ng's study, a comfortable OUT_SET value is about $25^{\circ} \mathrm{C}$, and thermal comfort reduces substantially when it is lower than $20^{\circ} \mathrm{C}$ or above $40^{\circ} \mathrm{C}$ [21]. In this study, an OUT_SET was calculated for all design models. As described above, the input data were obtained from field measurements, where the average radiation temperature was $52.7^{\circ} \mathrm{C}$. Further inputs were that an upper outer garment is 0.15 clo, trousers are $0.06 \mathrm{clo}$, and the metabolic rate is 1.9 met.

\section{Thermal Parameters}

In order to study the thermal comfort of a riverside residential settlement, it is essential to obtain thermal parameters that are the AT, WV, and the RH, which were got through the simulations by using the ANSYS FLUENT [20]. The Table 1 also shows the average values of AT, WV, and RH calculated by extracting values from $1 \mathrm{~m} \times 1 \mathrm{~m}$ grids of AT, $\mathrm{WV}$, and $\mathrm{RH}$ distributions. Based on the average values, the relationships between the $\mathrm{AT}$ and $\mathrm{WV}$, and between the $\mathrm{WV}$ and $\mathrm{RH}$, were derived as presented in the Figure 1.



(a) AT \& WV

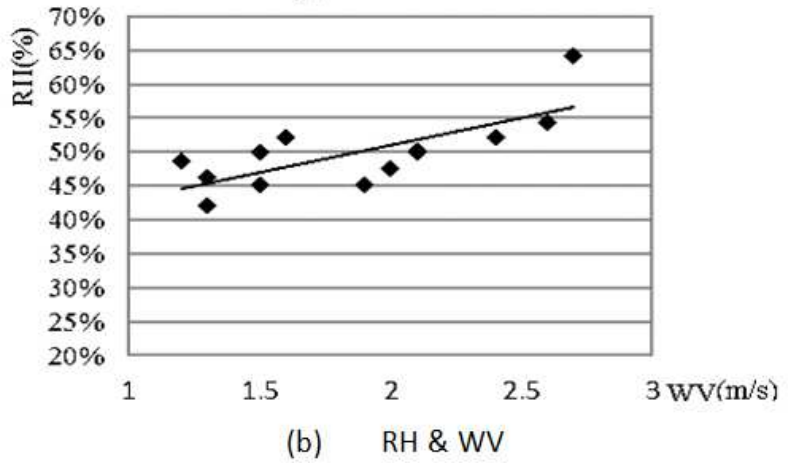

Figure 1. Relationships between $A T \& W V$, and $R H \& W V$.

It can be seen that a negative relationship exists between the AT and WV indicating that with a higher WV, the AT is lower. High wind speed would reduce air temperature. However, a positive relationship exists between the WV and $\mathrm{RH}$ although the difference is not high as the Table 1 shows that the RH is only varied within $45-64 \%$, which demonstrates that a higher wind speed would not bring too much moisture to the settlement. The results indicate that when a riverside residential settlement has a high air temperature, it usually has a low wind speed as well as a low relative humidity.

From Table 1, it is also found that the determinant layout models (A-a) have higher AT and lower WV than the enclosed models (A-b) and the point group models (A-c), illustrating that the determinant layout is bad to the thermal comfort of a riverside residential settlement. This is might be related with a positive relationship exists between the RH and the WV as the Figure 1 shows. Although a rather high $\mathrm{RH}$ could cause thermal discomfort, this is not a case in this study because the greatest RH is only $64 \%$, which is not high to produce 'muggy' atmosphere. Around such RH values, higher WV with higher $\mathrm{RH}$ would cool the temperature more than the dry wind do and provide better thermal comfort. Since the RH is not high and changed much in this study, the following analysis would only focus on discussing AT and WV.

As the determinant layout is widely used in a real world, further explorations were made through comparing the A-a with the $\mathrm{B}, \mathrm{C}$, and $\mathrm{D}$ design models that represent variation situations of a determinant layout. By comparing the A-a, B, C and D design models' AT and WV in the Table 1, it is found that the B models have a rather lower AT and higher WV than the other models. The result illustrates that a better design layout for a determinant is to make the buildings have an angle to the river. The closer the angle is to $90^{\circ}$, the better thermal 
comfort would achieve. It is found that the optimization angle is the $90^{\circ}$ (the B-2) as shown in the Table 1. Unfortunately, this design layout is not good for the individual building as having a bad view to the river and also bad for obtaining sunlight. From an overall perspective of a design, this design layout should not be adapted directly, more situations have to be considered.

Besides the $\mathrm{B}$ models, the $\mathrm{C}$ and $\mathrm{D}$ models also have slightly better thermal comfort than a regular determinant layout model. The thermal comfort of the $\mathrm{C}$ and $\mathrm{D}$ models are slightly better than that of the A-a1, A-a2 as having rather lower AT and higher WV. This means to the determinant layout design, if lowering the closer river's building height or setting open spaces, a better thermal comfort could be achieved. A reason might be that the $\mathrm{C}$ and $\mathrm{D}$ design models provide a better condition for inducing the wind from river to the settlement. The D models present different arrangements of open space in the settlement. It is found that the front arrangement (the open space close to the river) has slightly better thermal comfort than the rear arrangement (the open space far away from the river).

When comparing all the determinant layout models, it is found that the models having an angle (the B models) to the river have better thermal comfort than the others. This is because they have a lower AT and higher WV but similar RH with the others. The worst thermal comfort is found in the
A-a1 and A-a2 model as having a higher AT and lower WV. Except the B models and A-a1 and A-a2 models, the other determinant layout models including the $\mathrm{A}-\mathrm{a} 3$ and the $\mathrm{B}$ and the $\mathrm{C}$ models have similar AT and $\mathrm{WV}$ that is around $35^{\circ} \mathrm{C}$ and $1.5 \mathrm{~m} / \mathrm{s}$ indicating they have close thermal comfort. The results illustrate that the regular determinant layout, the right and left aligned determinant layout design are bad to reach a thermal comfort for a riverside residential settlement, whereas the determinant layout design with the buildings having an angle to the river are good to reach a thermal comfort.

\section{Results}

To assess the thermal comfort of a riverside residential settlement in terms of various design layouts, the SET index was applied. The calculated average OUT_SET along with the AT, RH, and WV of each design models are shown in the Table 2. It can be seen that the lowest OUT_SET is $30.6^{\circ} \mathrm{C}$. Nikolopoulou et al. found that thermal neutrality for outdoor conditions is $27^{\circ} \mathrm{C}$ in summer [10], and Lin and $\mathrm{Ng}$ found it is higher in a subtropical area [21]. On this basis, it is assumed that when an OUT_SET is above $30^{\circ} \mathrm{C}$, the thermal discomfort would occur. As all the OUT_SET in this study are above $30^{\circ} \mathrm{C}$ as shown in the Table 2 , it is then considered that the lower the OUT_SET, the better the thermal comfort is.

Table 2. Thermal parameters and OUT_SET to different design layouts.

\begin{tabular}{lllll}
\hline Model & Layout & Avg. AT & Avg. RH & Avg. WV \\
\hline A-a1 & Regular determinant & $36.1^{\circ} \mathrm{C}$ & $48.7 \%$ & $1.2 \mathrm{~m} / \mathrm{s}$ \\
A-a2 & Back and front aligned determinant & $36.5^{\circ} \mathrm{C}$ & $46.3 \%$ & $1.3 \mathrm{~m} / \mathrm{s}$ \\
A-a3 & Right and left aligned determinant & $35^{\circ} \mathrm{C}$ & $50 \%$ & $1.5 \mathrm{~m} / \mathrm{s}$ \\
A-b1 & Enclosed & $33.4^{\circ} \mathrm{C}$ & $45.5^{\circ} \mathrm{C}$ & $1.9 \mathrm{~m} / \mathrm{s}$ \\
A-b2 & Loose enclosed & $31.3^{\circ} \mathrm{C}$ & $34.1^{\circ} \mathrm{C}$ \\
A-c1 & Regular point group & $32.8^{\circ} \mathrm{C}$ & $54.5 \%$ & $2.6 \mathrm{~m} / \mathrm{s}$ \\
A-c2 & Irregular point group & $33.6^{\circ} \mathrm{C}$ & $52.3 \%$ & $2.4 \mathrm{~m} / \mathrm{s}$ \\
B-1 & $45^{\circ}$ determinant & $33.8^{\circ} \mathrm{C}$ & $47.7 \%$ & $2.0 \mathrm{~m} / \mathrm{s}$ \\
B-2 & $90^{\circ}$ determinant & $33.1^{\circ} \mathrm{C}$ & $50.1 \%$ & $2.1 \mathrm{~m} / \mathrm{s}$ \\
B-3 & $135^{\circ}$ determinant & $34.2^{\circ} \mathrm{C}$ & $64.4 \%$ & $2.7 \mathrm{~m} / \mathrm{s}$ \\
C & Front lower than rear & $35.3^{\circ} \mathrm{C}$ & $50.1 \%$ & $31.8^{\circ} \mathrm{C}$ \\
D-1 & Front open space determinant & $35.5^{\circ} \mathrm{C}$ & $52.3 \%$ & $32.6^{\circ} \mathrm{C}$ \\
D-2 & Back open space determinant & $35.9^{\circ} \mathrm{C}$ & $45.7^{\circ} \mathrm{C}$ \\
\hline
\end{tabular}

\subsection{Thermal Comfort Differences in Terms of Design Layout}

According to above analyses, it is known that the determinant layouts usually have a bad thermal comfort except the ones which buildings having an angle to the river (the B models). The result is similar if looking at the average OUT_SET. Comparing the average value of OUT_SET, it is found that the A-b, A-c and B have the better thermal comfort than the others. The result indicates that these layout designs would help to reach better thermal comfort to the riverside residential settlement. Amongst them, the best design layout for the thermal comfort is the loose enclosed layout (the A-b2 model) as having the smallest OUT_SET. However, the worst one is the right and left aligned determinant layout (the A-a2 model) as having the largest OUT_SET.
To the usually used regular determinant layout, the approach of tilting the buildings with an angle to the river, arranging open space, lowering the riverside buildings' height are useful to improve the thermal comfort of a riverside residential settlement. To the enclosed layout (the A-b models), the result shows that the loose enclosed (the A-b2) has better thermal comfort with a $30.6^{\circ} \mathrm{C}$ OUT_SET. To the point group layout (the A-c models), it is found that the regular point group has better thermal comfort with a $31.8^{\circ} \mathrm{C}$ OUT SET. Comparing the thermal comfort of all the study design models, the best one is the A-b2 (the loose enclosed layout) and then the A-c1 (the regular point group layout). The worst ones are the $\mathrm{A}-\mathrm{a} 1$ and the $\mathrm{A}-\mathrm{a} 2$ that has an average OUT_SET around $35^{\circ} \mathrm{C}$.

\subsection{Relationships of SET with Other Thermal Parameters}

In the Table 2, it can be seen that OUT_SET varies with AT 
and WV. The one with a smaller OUT_SET usually has a smaller AT and larger WV. As the change of the RH is not big and the value is neither too high nor too low, the RH is not discussed in the study. The Figure 2 shows the relationship of the OUT_SET and AT, and the relationship of the OUT_SET and WV. It is found that a positive relationship exists of the OUT_SET and AT, whereas a negative exists of the OUT_SET and $\bar{W}$ V. The relationship of the OUT_SET and AT is linear indicating that when the AT is higher the OUT_SET is also higher. A reason might be that high wind would accelerate water evaporation mitigating air temperature, which benefits to lower the OUT_SET when the RH is similar.

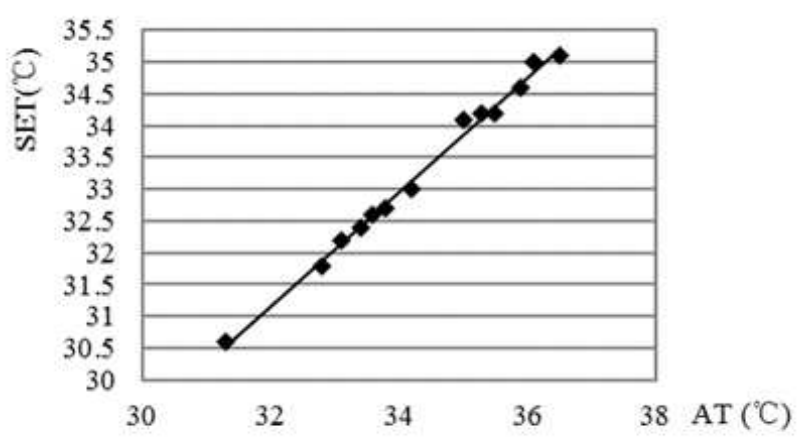

(a) AT \& OUT_SET

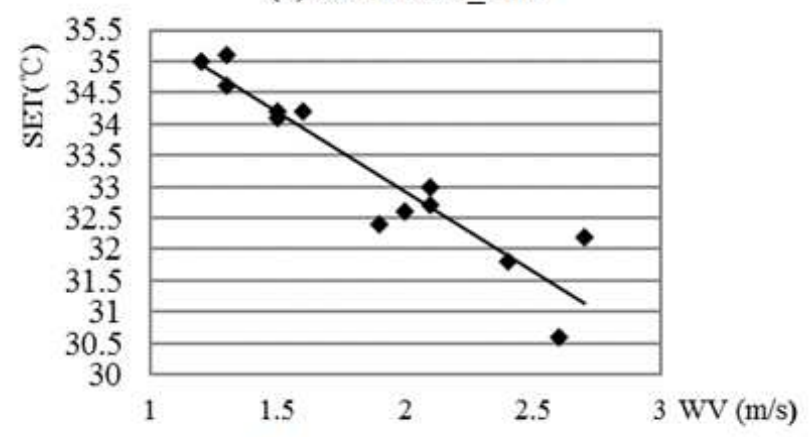

(b) WV \& OUT_SET

Figure 2. Relationships between AT\&OUT_SET, and WV\&OUT_SET.

Apparently, it can be concluded that a good design layout for a riverside residential settlement is the one that benefits to draw the riverside wind towards the settlement as the riverside wind brings moisture to cool air temperature. In this process, a high wind velocity is critical, as it could take out surplus humidity from the environment. Therefore, a good design layout for the thermal comfort of a riverside residential settlement is to encourage the riverside wind to penetrate and spread the whole settlement. As the A-a, C and D models generally contain a long building façade blocking the riverside wind penetration, they are not conducive to the thermal comfort. However, the other models shorten the building's length towards the river and provide opportunities for the wind penetration, they are conducive to the thermal comfort.

\section{A Case Study}

According to the above results, when design layout of a riverside residential settlement is good to induce the riverside wind to penetrate and spread through the settlement, it is helpful to reach a better thermal comfort. Comparing the three primary design layouts, the enclosed and the point group layouts are better than the determinant layout. For the determinant layout, it is found that tilting the buildings and making them having an angle to the river is the best way to reach the thermal comfort although lowering the height of the riverfront buildings or setting up open space could also slightly improve the thermal comfort. A key point here is to encourage the riverside wind going through the whole settlement. Moreover, the efficiency of above approaches for the design layout to the thermal comfort of a riverside residential settlement has been examined by a case study in the Nan Hua Cun, a riverside residential settlement in Shenzhen, China.

\subsection{The Original Layout of the Nan Hua Cun and Its Thermal Environment}

The Nan Hua Cun is located in Shenzhen Luo Hu District. The area has a subtropical weather and is adjacent to Hong Kong. The settlement was built in 2008. The Shenzhen River is just on its south-east side. The original layout of the settlement is the irregular point group layout as can be seen in the Figure 3. There is an open space in the back of the settlement, which is far away from the river. The buildings are facing the south direction but not the river. Generally speaking, the original layout of the settlement is not good for inducing the riverside wind passing through the area.

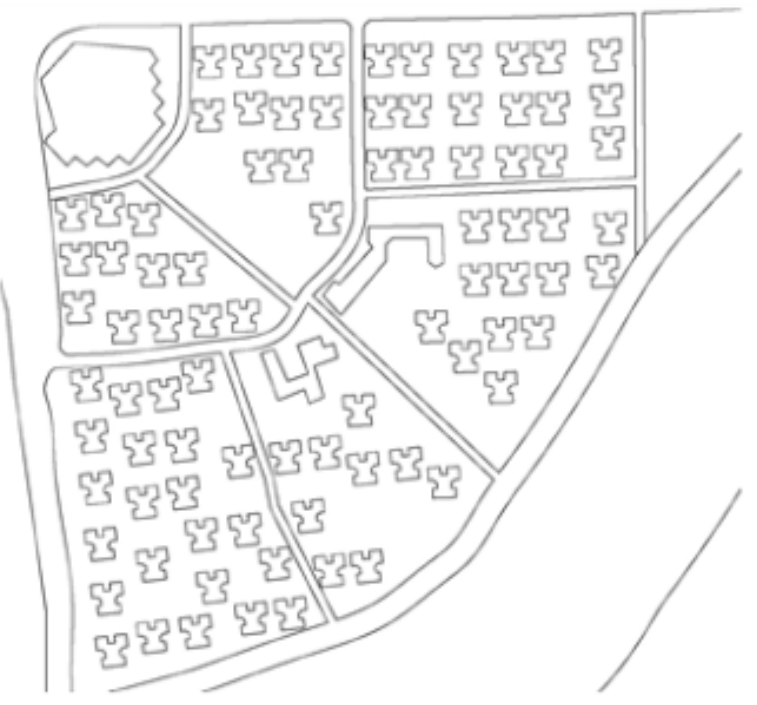

Figure 3. The original layout of the Shenzhen Nan Hua Cun.

Using the same simulation model as developed before, the distributions of AT, WV, and $\mathrm{RH}$ were obtained. These are given in the Table 3 along with the average values of AT, WV, $\mathrm{RH}$, as well as OUT_SET. It can be seen that the average value of AT is $35.2^{\circ} \mathrm{C}, \overline{\mathrm{WV}}$ is $1.1 \mathrm{~m} / \mathrm{s}$, RH is $51.2 \%$, and the OUT_SET is $34.7^{\circ} \mathrm{C}$, which is higher than a proper value of $25^{\circ} \mathrm{C}$ to the outdoor thermal comfort [21]. This means that the main works for reaching thermal comfort of the Nan Hua Cun is to lower the OUT_SET. 
Table 3. Thermal parameters and OUT_SET to the Nan Hua Cun.

\begin{tabular}{|c|c|c|c|}
\hline AT & WV & RH & OUT_SET \\
\hline $\begin{array}{l}15 \\
\equiv \\
\equiv\end{array}$ & & 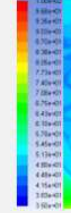 & $34.7^{\circ} \mathrm{C}$ \\
\hline $35.2^{\circ} \mathrm{C}$ & $1.1 \mathrm{~m} / \mathrm{s}$ & $51.2^{\circ}$ & \\
\hline
\end{tabular}

\subsection{The Optimization Design Layout of the Nan Hua Cun and Its Thermal Environment}

To improve the thermal comfort in the Nan Hua Cun, several approaches have been adapted based on the study results of the design layouts of a riverside residential settlement in terms of thermal comfort.

After evaluating the original layout of the Nan Hua Cun, it is found that the irregular point group layout is not the better one of the point group layout for getting thermal comfort. In addition, the buildings do not face the river that would block the riverside wind spread through the settlement. Furthermore, the original open space is set in the back of the settlement. These are not good for encouraging the riverside wind penetrating and spreading. An optimization layout was then proposed by using the above results. Firstly, the buildings were re-arranged to have a regular point group layout; secondly, the buildings were changed to face the river. Moreover, the open space was re-arranged in front close to the river. The optimization layout and original one is shown in the Figure 4 . The thermal comfort of the optimization design layout has been compared with that of the original.

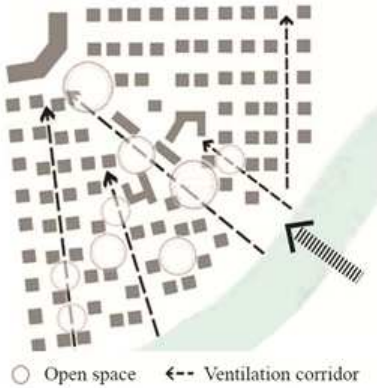

(a) Original layout

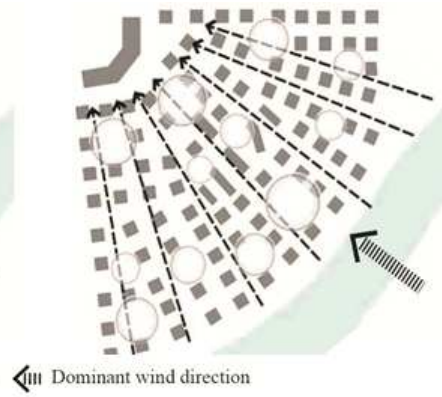

(b) Optimization design layout
Figure 4. Layout of the Nan Hua Cun.

Table 4 shows the distributions of AT, WV, RH, and OUT_SET for the optimization design layout of the Nan Hua Cun. Obviously, the thermal comfort has been improved as a lower OUT_SET has obtained. The average values of AT, WV, and $\mathrm{RH}$ for the optimization layout of the Nan Hua Cun are $33.4^{\circ} \mathrm{C}, 1.6 \mathrm{~m} / \mathrm{s}$ and $54.3 \%$. Comparing to the original one, its AT is lower and WV is higher presenting a better thermal comfort. The average OUT_SET of the optimization design layout is $33.1^{\circ} \mathrm{C}$, which is $1.6^{\circ} \mathrm{C}$ lower than that of the original layout, also illustrating a better thermal comfort.
Table 4. Thermal parameters and OUT_SET to the optimization design of the Nan Hua Cun.

\begin{tabular}{llll}
\hline AT & WV & RH & OUT_SET \\
\hline & & & \\
& & & $33.1{ }^{\circ} \mathrm{C}$ \\
$33.4^{\circ} \mathrm{C}$ & $1.6 \mathrm{~m} / \mathrm{s}$ & $54.3 \%$ & \\
\hline
\end{tabular}

\subsection{Thermal Environment and Comfort According to the Optimization Layout}

Table 5 compares the average AT, RH, WV, and OUT_SET of the original layout and the optimization layout of the Nan Hua Cun. It is found that the optimization layout has reached a better thermal comfort with a lower AT and OUT SET and a higher WV with a similar RH. Although the optimization layout has a slightly higher RH, it barely influences the thermal comfort because the value is only $54.3 \%$ far away from the uncomfortable level. The outcome indicates that the optimization design layout does enhance the thermal comfort, which proves the efficiency of the approaches obtained from the above study.

Table 5. Comparison of the original layout and optimization design layout.

\begin{tabular}{lllll}
\hline Layout & Avg. AT & Avg. RH & Avg. WV & Avg. OUT_SET \\
\hline Original & $35.2^{\circ} \mathrm{C}$ & $51.2 \%$ & $1.1 \mathrm{~m} / \mathrm{s}$ & $34.7^{\circ} \mathrm{C}$ \\
Optimization & $33.4^{\circ} \mathrm{C}$ & $54.3 \%$ & $1.6 \mathrm{~m} / \mathrm{s}$ & $33.1^{\circ} \mathrm{C}$ \\
\hline
\end{tabular}

In order to argue that the proposed approaches are more useful to a riverside residential settlement rather than a non-riverside residential one, a comparison has been made. Two design models were built using the same design layout but one is near a river as the situation of the Nan Hua Cun has, the other is supposed not adjacent to a river. The results are shown in the Table 6.

Table 6. Comparison of a riverside and a non-riverside situation.

\begin{tabular}{lllll}
\hline & Riverside & \multicolumn{3}{c}{ Non-riverside } \\
\cline { 2 - 4 } & Distribution & Avg. value & Distribution & Avg. value \\
\hline & & & \\
AT & $33.4^{\circ} \mathrm{C}$ & & $36.4^{\circ} \mathrm{C}$ \\
\hline
\end{tabular}




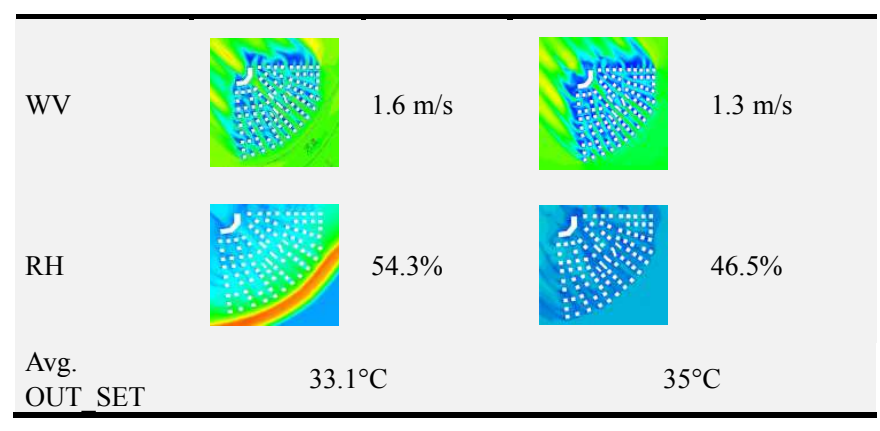

It can be seen that the riverside residential settlement has the better thermal comfort than the non-riverside as having a higher AT and lower WV. To the RH, there is not much difference between the riverside and the non-riverside although the riverside has a slightly higher $\mathrm{RH}$ as the effect of water evaporation. Especially, the OUT_SET of the riverside residential settlement is much lower than the non-riverside one. The OUT SET of the non-riverside is even higher than the Nan Hua Cun (a riverside residential settlement without an optimization layout). In the Table 6 , it can be seen if the approaches from above study were used in a non-riverside residential settlement, the average value of the OUT_SET would be $35^{\circ} \mathrm{C}$, which is $1.9^{\circ} \mathrm{C}$ higher than that of a riverside residential settlement.

\section{Conclusion}

This paper has studied how to use waterbody as a climatic regulator to modulate the thermal environment and enhance thermal comfort in a riverside residential settlement in the subtropical area of the southern China. According to typical design models, a number of thermal simulations were made to obtain the distributions of the air temperature (AT), wind velocity (WV), and relative humidity (RH). The average values of the AT, WV, RH, as well as the Outdoor Standard Effective Temperature (OUT_SET) for a riverside residential settlement due to different design layouts were also calculated. It is found that the enclosed layout and point group layout have good thermal comfort, whereas the determinant layouts usually have bad thermal comfort except the ones which buildings having an angle to the river. To the enclosed layout, the loose one has better thermal comfort than the normal enclosed one. To the point group layout, the regular one has better thermal comfort than the irregular one.

Although a determinant layout usually is a bad to the thermal environment of a riverside residential settlement, improvement could be made by changing the buildings orientation to the river. Besides, lowering the heights of riverside buildings and creating front open space to the river could also slightly improve the thermal comfort although they are not that efficient comparing to changing the buildings' orientation.

One guideline is to minimise the hindrance of wind penetrating and spreading. This could help to accelerate water evaporation and cooling the air temperature. Using the approaches obtained from the study results based on the typical design models, a case study of the Shenzhen Nan Hua
Cun was made. It is found that the approaches are useful to achieve the thermal comfort to a riverside residential settlement in the subtropical regions of the southern China.

\section{Acknowledgements}

This research is supported by the China National Science Foundation (50879015) and (71371060). The authors would like to acknowledge all the research members worked in this project.

\section{References}

[1] Liu, W. W., Y. X. Zhang and Q. H. Deng (2016). The effects of urban microclimate on outdoor thermal sensation and neutral temperature in hot-summer and cold-winter climate. Energy and Buildings 128, 190-197.

[2] Wang, Y. S., Q. M. Zhan and W. L. Ouyang (2019). How to quantify the relationship between spatial distribution of urban waterbodies and land surface temperature. Science of the Total Environment 671, 1-9.

[3] Keery, J., A. Binley, N. Crook and J. W. N. Smith (2007). Temporal and spatial variability of groundwater-surface water fluxes: Development and application of an analytical method using temperature time series. Journal of Hydrology $336,1-16$.

[4] Theeuwes, N. E., A. Solcerová and G. J. Steeneveld (2013). Modelling the influence of open water surfaces on the summertime temperature and thermal comfort in the city. J. Geophysical Research: Atmospheres 118, 8881-8896.

[5] Lin, H., J. Q. Niu, H. Q. Ma and Y. Fan (2017). Urban water body reduction of heat island effects - A case study of Nanjng City. J. Xinyang Normal University, Natural Science Edition 30 (2), 234-238.

[6] Hathway, E. A., S. Sharples (2012). The interaction of river and urban form in mitigating in the Urban Heat Island effect: A UK case study. Building and Environment 58, 14-22.

[7] Song, X. C., J. Liu and L. Yu (2016). Pedestrian environment prediction with different types of on-shore building distribution. Journal of Central South University 23, 955-968.

[8] Gaitani, N., G. Mihalakakou and M. Santamouris (2007). On the use of bioclimatic architecture principles in order to improve thermal comfort conditions in outdoor spaces. Building and Environment 42 (1), 317-324.

[9] Martínez-Arroyo, A. and E. Jáuregui (2000). On the environmental role of urban lakes in Mexico City. Urban Ecosystems 4, 145-166.

[10] Nikolopoulou, M., N. Baker and K. Steemers (2001). Thermal comfort in outdoor urban spaces: understanding the human parameter. Solar Energy 70 (3), 227-235.

[11] ASHRAE. Handbook of Fundamentals: Physiological Principles, Comfort, Health. America Society of Heating, Refrigeration and Air-Conditioning Engineers, New York 1997.

[12] Ruiz, M. A., and E. N. Correa (2015). Adaptive model for outdoor thermal comfort assessment in an Oasis city of arid climate. Building and Environment 85, 40-51. 
[13] Chen, L., and E. Ng (2012). Outdoor thermal comfort and outdoor activities: A review of research in the past decade. Cities 29 (2), 118-125.

[14] Ahmed, K. S. (2003). Comfort in urban spaces: defining the boundaries of outdoor thermal comfort for the tropical urban environments. Energy and Buildings 35 (1), 103-110.

[15] Yang, W., N. H Wong and S. K. Jusuf (2013). Thermal comfort in outdoor urban spaces in Singapore. Building and Environment 59 (3), 426-435.

[16] Makaremi, N., E. Salleh, M. Z. Jaafar, et al. (2012). Thermal comfort conditions of shaded outdoor spaces in hot and humid climate of Malaysia. Building and Environment 48 (1), 7-14.

[17] Lin, B., X. F Li, Y. X. Zhu, et al. (2008). Numerical simulation studies of the different vegetation patterns' effects on outdoor pedestrian thermal comfort. Journal of Wind Engineering and Industrial Aerodynamics 96 (10-11), 1707-1718.

[18] Xi, T., Q. Li and A. Mochida (2012). Study on the outdoor thermal environment and thermal comfort around campus clusters in subtropical urban areas. Building and Environment 52 (6), 162-170.
[19] Spagnolo, J., and R. D. Dear (2003). A field study of thermal comfort in outdoor and semi-outdoor environments in subtropical Sydney Australia. Building and Environment 32, 721-738.

[20] Cohen, P., O. Potchter and A. Matzarakis (2013). Human thermal perception of Coastal Mediterranean outdoor urban environments. Applied Geography 37, 1-10.

[21] E. Ng, Designing high-density cities for social and environmental sustainability. Earthscan, London: Sterling, VA, 2009.

[22] Kántor, N., and J. Unger (2010). Benefits and opportunities of adopting GIS in thermal comfort studies in resting places: An urban park as an example. Landscape and Urban Planning 98 (1), 36-46.

[23] Hwang, R. L., T. P. Lin and A. Matzarakis (2011). Seasonal effects of urban street shading on long-term outdoor thermal comfort. Building and Environment 46 (4), 863-870.

[24] Lin, T. P. (2009). Thermal perception, adaptation and attendance in a public square in hot and humid regions. Building and Environment 44, 2017-2026. 